\title{
Sorption of BTEX on a nanoporous composite of SBA-15 and a calcined hydrotalcite
}

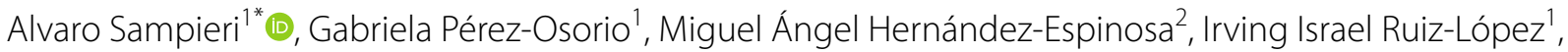 \\ Mayra Ruiz-Reyes ${ }^{1}$, Janette Arriola-Morales ${ }^{1}$ and Rocío lliana Narváez-Fernández ${ }^{1}$
}

\begin{abstract}
Benzene, toluene, ethylbenzene, and p-xylene (BTEX) are hazardous volatile organic compounds mostly released from fuel combustion, paint gas emissions, and biomass burning. In this work, it is studied the BTEX sorption influence on the surface reactivity of a new kind of nanoporous composite, prepared via an in situ functionalization of SBA-15 with a Mg-Al calcined hydrotalcite $\left(\mathrm{HT}_{\mathrm{C}}\right.$ ). During its preparation, $\mathrm{Mg} / \mathrm{Al}$ mixed oxides are indeed formed and dispersed on the SBA-15 surface with non-blockage porosity. Furthermore, the physicochemical surface properties are exalted from its precursors and it is synergistically favorable for the BTEX sorption at low pressure and temperature.
\end{abstract}

Keywords: BTEX sorption, SBA-15, Mg/Al oxides, Nanoporous composite

\section{Introduction}

Air pollution has become a notorious worldwide issue of major significance with an arising of uncontrolled pollutant emissions originated by several chemical processes that modify both air quality and natural cycles. The volatile organic compounds (VOC) that can change from liquid to gas at room temperature are highly toxic pollutants. Household and industrial solvents, paints and the burning of fossil fuels are the main sources of VOC emissions. They contribute to photochemical smog in big cities and have an impact on the environment and health of humans [1]. Although there are several studies on VOC catalytic elimination [2,3], the sorption process is always preferred due to the less cost and recovering of the VOC [4]. For instance, metal-organic frameworks (MOFs), with a large surface area $\left(5870 \mathrm{~m}^{2} / \mathrm{g}\right.$ of BET area) and a $1.85 \mathrm{~cm}^{3} / \mathrm{g}$ total pore volume, have proved to be an effective choice for VOC removal, especially for those molecules presenting steric hindrance as xylenes and ethylbenzene [5]. However, using MOFs as adsorbents is still an unaffordable choice in terms of their preparation costs. Micro and mesoporous materials based on $\mathrm{SiO}_{2}$

*Correspondence: alvaro.sampieri@gmail.com; alvaro.sampieri@correo. buap.mx

1 Facultad de Ingeniería Química, Benemérita Universidad Autónoma de Puebla, Ciudad Universitaria, 72570 Puebla, PUE, Mexico

Full list of author information is available at the end of the article and functionalized with $\mathrm{Ag}$ or $\mathrm{Cu}$ has been studied to sorb benzene, toluene, and $p$-xylene (BTX) [6] showing that toluene and $p$-xylene adsorption can be stopped in the case of $\mathrm{Cu} / \mathrm{SiO}_{2}$, because of a steric hindrance due to an ink-bottle pore shape of such material. BTX sorption it was also carried out by using amine modified KIT-6 and SBA-15 presented highly adsorption increasing with an increase in the pressure [7]. However, a poor benzene adsorption was observed due to the hydrophobicity of the KIT- 6 whereas $m$-xylene and toluene presented stronger hydrophobic interaction with the amine-modified material. In the same way, a SBA-15, functionalized with polyvinyl benzene [7] or phenyltriethoxysilane [8], proves to be an excellent VOC hydrophobic adsorbent of toluene, benzene and cyclohexane with no steric hindrance. Cobalt supported on a calcined hydrotalcite was used as a catalyst in the toluene oxidation using the memory effect of $\mathrm{Mg}-\mathrm{Al}$ hydrotalcite [9]. Hydrotalcites are lamellar materials showing basic properties without significant specific surface area and mesoporosity [10]. Hence, large molecules cannot reach the most of the anchorage sites. If an anionic clay is combined with a mesoporous material (i.e. SBA-15), a great adsorbent can be synthesized $[11,12]$. For instance, the SBA-15 is a mesoporous material with a specific surface area larger than $700 \mathrm{~m}^{2} / \mathrm{g}$ and a $0.8 \mathrm{~cm}^{3} / \mathrm{g}$ of pore volume, both are ideal characteristics for a VOC adsorbent. However, the SBA-15 exhibits poor 
surface reactivity due to a reduced number of anchor sites (silanol groups). In this paper, the SBA-15 surface functionalized with a $\mathrm{Mg}-\mathrm{Al}$ calcined hydrotalcite ( $\mathrm{HTc}$ ) is carried out. After the calcination of this nanocomposite, $\mathrm{Al}-\mathrm{Mg}-\mathrm{O}$ mixed oxides are dispersed on the SBA-15 surface, and the modification of its textural properties occurs. Indeed, HTc presents a higher chemical reactivity than that of the SBA-15, but a much lower specific area (ca. $74 \mathrm{~m}^{2} / \mathrm{g}$ ) and a very small mesoporous volume (ca. $0.20 \mathrm{~cm}^{3} / \mathrm{g}$ ). The accurate combination of such materials, with non-organic functionalization, can be readily performed to produce a nanoporous composite with physicochemical properties that have a synergistic influence on the benzene, toluene, ethylbenzene, and xylene sorption.

\section{Experimental}

\subsection{Material preparation}

\subsubsection{Sba-15}

The SBA-15 preparation was carried out following the methodology proposed by Zhao et al. [13]. In a polyethylene bottle, $16 \mathrm{~g}$ of template, Pluronic 123 $(\mathrm{EO})_{20}(\mathrm{PO})_{70}(\mathrm{EO})_{20}$ (Sigma-Aldrich), were mixed with $474 \mathrm{~mL}$ of a $2 \mathrm{M} \mathrm{HCl}$ (J. T. Baker, 37\%) solution. The mixture remained under stirring at room temperature until the apparent dissolution of the template. Subsequently, $34.4 \mathrm{~mL}$ of tetraethylortosilicate (TEOS, Sigma-Aldrich, 98\%) were gradually added into this polyethylene bottle and remaining under stirring at room temperature another $24 \mathrm{~h}$. The recipient was treated at $95{ }^{\circ} \mathrm{C}$ for $72 \mathrm{~h}$ into an oven. The solid was thus recovered by decantation, washed with distilled water and dried at $70{ }^{\circ} \mathrm{C}$. An amount of this sample was calcined at $550{ }^{\circ} \mathrm{C}$ in air for $6 \mathrm{~h}$ to eliminate the organic template.

\subsubsection{Mg/Al mixed oxides}

The preparation of a $\mathrm{Mg} / \mathrm{Al}$ hydrotalcite with a 2:1 mol ratio was achieved by using a microwave-assisted coprecipitation method to obtain a material whose formulation is $\mathrm{Mg}_{6} \mathrm{Al}_{3}(\mathrm{OH})_{18} \mathrm{NO}_{3} \cdot 4 \mathrm{H}_{2} \mathrm{O}$ [14]. A $1.5 \mathrm{M}$ solution was prepared from $\mathrm{Mg}\left(\mathrm{NO}_{3}\right)_{2} \cdot 6 \mathrm{H}_{2} \mathrm{O}$ and $\mathrm{Al}\left(\mathrm{NO}_{3}\right)_{3} \cdot 7 \mathrm{H}_{2} \mathrm{O}$, (both from Aldrich, 98\%). A precipitating solution of $\mathrm{NH}_{4} \mathrm{OH}(2 \mathrm{M})$ was also prepared. Both solutions were dropwise into a flask under stirring and remaining a constant $\mathrm{pH}$ 9. The coprecipitated salts were stirred for $24 \mathrm{~h}$ at room temperature. The solid was recovered by filtration, washed and dried at $70{ }^{\circ} \mathrm{C}$. Finally, the dried white solid was calcined at $550{ }^{\circ} \mathrm{C}$ for $6 \mathrm{~h}$ to obtain the $(\mathrm{Mg}-$ Al-O) mixed oxides, the sample was labeled as HTc.

\subsubsection{SBA-15/HT $\mathrm{C} 25_{\text {composite }}$}

The composite was prepared by combining a suitable amount of SBA-15 with a $\mathrm{Mg}-\mathrm{Al}$ nitrated hydrotalcite to obtain a $80 / 25 \mathrm{wt} \%$ nominal ratio of the calcined composite [11]. 80 wt\% of non-calcined SBA-15 was placed into a flask containing $25 \mathrm{~mL}$ of distilled water and dispersed by stirring during an hour. Subsequently, the complementary amount of $\mathrm{Mg}-\mathrm{Al}$ hydrotalcite (ca. $20 \mathrm{wt} \%$ ) was prepared on the SBA-15 dispersion following the same procedure mentioned in the above section. The dried composite was calcined at $550{ }^{\circ} \mathrm{C}$ for $6 \mathrm{~h}$ and labeled as $\mathrm{SBA}-15 / \mathrm{HT}_{\mathrm{C} 25}$.

\subsection{Materials characterization}

$\mathrm{SBA}-15, \mathrm{HT}_{\mathrm{C}}$, and SBA-15/ $\mathrm{HT}_{\mathrm{C} 25}$ samples were characterized by X-ray diffraction (XRD) by using a Bruker D8 equipment with $\mathrm{Cu} K \alpha$ radiation, at scanning ranges from $0.7^{\circ}$ to $3^{\circ}(2 \theta)$ for small angles and from $5^{\circ}$ to $70^{\circ}(2 \theta)$ for wider angles. Nitrogen adsorption at $77 \mathrm{~K}$ was carried out with a Micromeritics ASAP 2010 equipment between relative accuracy ranges, $P / P_{0}$, from 0.06 up to 0.99 with 0.015 increases. Previously, the samples were degassed at $90{ }^{\circ} \mathrm{C}$ for $10 \mathrm{~h}$ until a $0.05 \mathrm{mmHg}$ vacuum pressure was reached.

\subsection{BTEX adsorption tests}

The adsorption of benzene, toluene, ethylbenzene or $p$-xylene (BTEX) was carried out by using a SHIMADZU GC-14A gas chromatograph with a flame ionization detector (FID). A stainless steel chromatographic column (0.6 in diameter and $50 \mathrm{~cm}$ long) was packed with $0.1 \mathrm{~g}$ of each sample mixed with $0.2 \mathrm{~g}$ of ground glass, previously sieving (80/50 mesh). During chromatographic analyses, a high-purity $\mathrm{He}$ (99\% chromatographic degree) was used as carrying gas $\left(30 \mathrm{~cm}^{3} / \mathrm{min}\right)$. A pretreatment of samples with He was realized at $300^{\circ} \mathrm{C}$ for $1 \mathrm{~h}$. Table 1 shows the temperature intervals of the chromatograph devices during analyses, considering the VOC physical properties, Table 2 . On each adsorption test, $1 \mu \mathrm{L}$ of VOC was injected.

\subsubsection{Equilibrium models of adsorption isotherms}

The experimental data were used to model two popular adsorption isotherm equations: Freundlich and Langmuir. The Freundlich isotherm equation [16] was used as follows:

$$
\log a=\log k_{f}+\frac{1}{n} \log p
$$

Table 1 Temperature intervals for chromatograph devices

\begin{tabular}{llllll}
\hline & \multicolumn{5}{l}{ Temperature ${ }^{\circ} \mathbf{C}$} \\
\cline { 2 - 6 } & 1st & 2nd & 3rd & 4th & 5th \\
\hline Injector & 305 & 270 & 235 & 195 & 160 \\
Furnace & 300 & 260 & 225 & 185 & 150 \\
Detector & 315 & 285 & 245 & 205 & 170 \\
\hline
\end{tabular}


Table 2 Physical properties of VOC [15]

\begin{tabular}{lllllc}
\hline VOC & $\begin{array}{l}\text { Molecular weight }(\mathbf{M W}) \\
\mathbf{g} / \mathbf{m o l}\end{array}$ & $\begin{array}{l}\text { Kinetic diameter }(\boldsymbol{\sigma}) \\
\mathbf{n m}\end{array}$ & $\begin{array}{l}\text { lonizing potential } \\
(\mathbf{P}) \text { Ev }\end{array}$ & Radii (d) nm & $\begin{array}{l}\text { Boiling } \\
\text { temperature }{ }^{\circ} \mathbf{C}\end{array}$ \\
\hline Benzene & 78.11 & 0.65 & $9.2-9.7$ & 0.73 & 80.1 \\
Toluene & 92.14 & $0.65 / 0.89$ & 8.8 & 0.835 & 110.6 \\
$p$-Xylene & 106.16 & $0.98 / 1.05$ & 8.5 & 0.94 & 144 \\
Ethylbenzene & 106.16 & 0.98 & 8.5 & 0.94 & 136 \\
\hline
\end{tabular}

where $p$ is the equilibrium pressure when gas moles are adsorbed at temperature $\mathrm{T}$ in Kelvin degrees (K), $a$ is the adsorption capacity at equilibrium with the adsorbent, $k_{f}$ is Freundlich equilibrium constant that shows the adsorption capacity and the adsorbate affinity by the adsorbent, and $1 / n$ is defined as the rate of adsorbate saturation. Likewise, the Langmuir model isotherm equation [16] was used as follows.

$$
\frac{P}{a}=\frac{1}{K a_{m}}+\frac{P}{a_{m}}
$$

where $P$ is the system pressure, $a$ is the adsorbed volume at a certain pressure, $a_{m}$ is the maximum monolayer volume that the surface can adsorb at equilibrium and $K$ is the value of Langmuir constant. Both adsorption isotherm equations were fitted using experimental data with correlation coefficients greater than 0.9 for all isotherms. It is also known that at lower pressure, Also, Henry isotherm is a short form of the Langmuir isotherm, represented as follow:

$$
a=K_{H} P
$$

where $K_{H}$ is the Henry constant.

\subsubsection{Isosteric heat of adsorption}

The isosteric heat of adsorption $\left(q_{s t}\right)$ was estimated by using adsorption isotherms from the VOC at different temperatures. Isosteric heat of adsorption is the most used property for calculating fixed beds, which is given by the Clausius-Clapeyron equation 3 [6].

$$
\frac{\partial p}{\partial T_{a}}=\frac{q_{s t}(a)}{R T^{2}}
$$

The heat of adsorption can be determined from the isotherms acquired at different temperatures.

\section{Results and discussion}

\subsection{X-ray diffraction}

The diffractograms at small angles of the calcined hydrotalcite $\left(\mathrm{HT}_{\mathrm{C}}\right), \mathrm{SBA}-15$, and SBA-15/ $\mathrm{HT}_{\mathrm{C} 25}$, respectively, were recorded between $0.5^{\circ}$ and $5^{\circ} 2 \theta$, Fig. $1 \mathrm{a}$; the (100) diffraction signal it is observed at $0.87^{\circ} 2 \theta$ and it is characteristic of an interlayer distance of $10.1 \mathrm{~nm}$, of the SBA15 nanostructure. A similar, peak diffraction is observed at $0.90^{\circ} 2 \theta$, which belongs to an interlayer distance of $9.8 \mathrm{~nm}$. As expected, the $\mathrm{HT}_{C}$ shows no diffraction peaks at small angles. Instead, the recorded diffractogram at wider angles (between $5^{\circ}$ y $70^{\circ} 2 \theta$ ) for the HTc, Fig. 1b, shows the characteristic peaks of the periclase-type structure that belongs to the mixed oxides, $\mathrm{Mg}-\mathrm{Al}-\mathrm{O}$, at $42^{\circ}$ and $65^{\circ} 2 \theta$ (JCPDS 00-045-0946). For the SBA- 15 and the composite diffractograms, a rather wide shoulder is observed between $15^{\circ}$ and $30^{\circ} 2 \theta$. This kind of polycrystalline diffractogram is usually associated with the amorphous silica (JCPDS 00-076-912) that is the main component of the SBA-15 walls. However, no diffraction signal relating to the mixed oxides $(\mathrm{Mg}-\mathrm{Al}-\mathrm{O})$ are observed for the composite, SBA- $15 / \mathrm{HT}_{\mathrm{C} 25}$. Therefore, small $\mathrm{Mg}-\mathrm{Al}-\mathrm{O}$ particles may be homogeneously dispersed on the SBA-15 nanoporous surface [11].

\subsection{Nitrogen adsorption}

In Fig. $2 \mathrm{a}$ and $\mathrm{b}$, are respectively represented the nitrogen adsorption-desorption isotherms and the pore diameter distribution for the SBA-15, calcined hydrotalcite $\left(\mathrm{HT}_{\mathrm{C}}\right)$ and SBA- $15 / \mathrm{HT}_{\mathrm{C} 25}$ composite. Each isotherm is type IV, according to the IUPAC classification, indicating that materials present mainly mesoporous. The SBA- 15 and SBA-15/ $\mathrm{HT}_{\mathrm{C} 25}$ isotherms show an $\mathrm{H} 1$ hysteresis loop [17] at $\mathrm{P} / \mathrm{P}_{0}$ ranging from 0.5 to 0.75 , Fig. $2 \mathrm{a}$; it is associated to the mesoporous materials having tubular porous whit a narrow size distribution. Nevertheless, the $\mathrm{HT}_{\mathrm{C}}$ show an $\mathrm{H} 3$ hysteresis loop with a relative pressure interval from 0.64 to 0.90 , relating to the porous with laminar structure, as in clays [18].

The SBA-15 and SBA-15/HT $\mathrm{H}_{25}$ composite pore diameter distributions are rather similar as shown in Fig. 2b. As $\mathrm{N}_{2}$ adsorption-desorption isotherms present similar form curves, they can also be structurally analogous, denoting no mesoporous blocking. The SBA-15 presents a $6.88 \mathrm{~nm}$ main pore diameter with a slight decreasing in the composite one $(6.75 \mathrm{~nm})$. This 
a

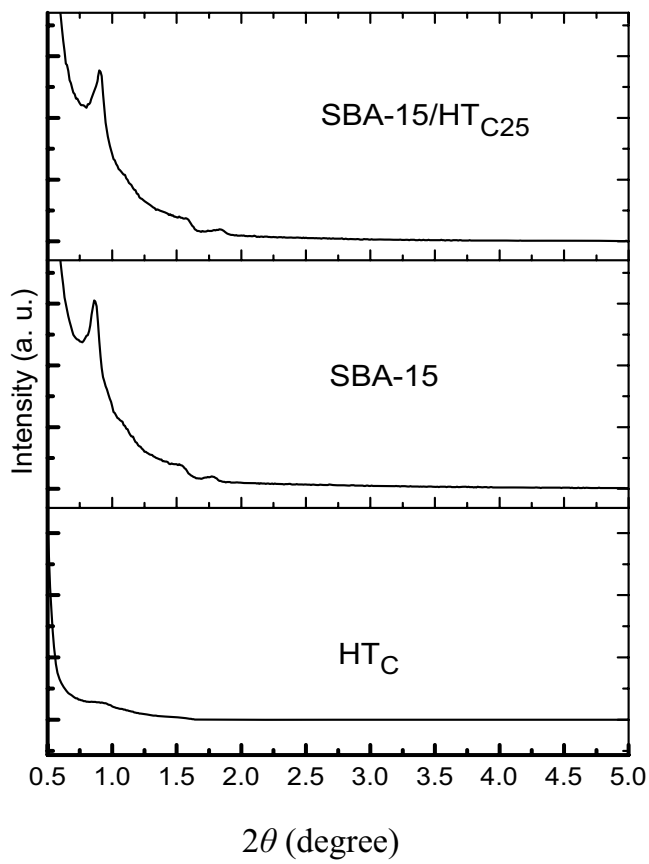

b

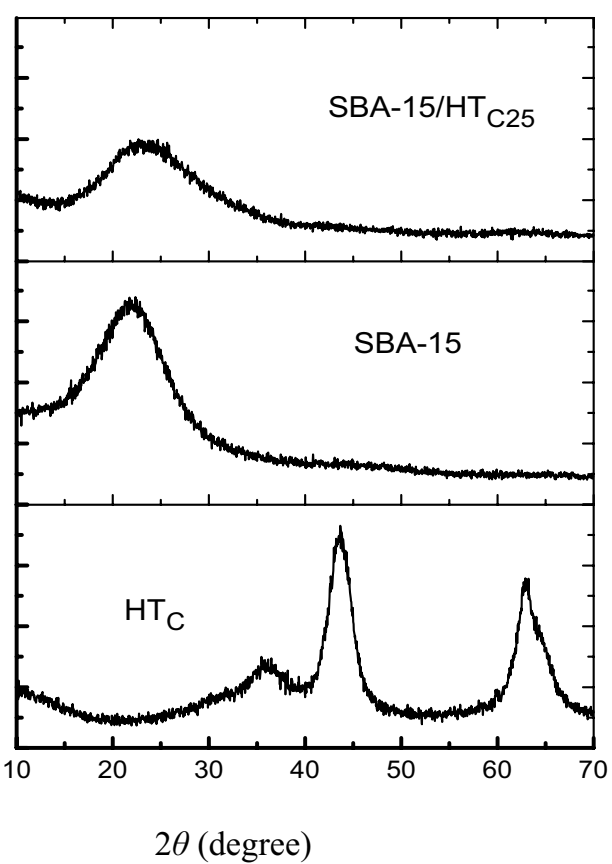

Fig. 1 Diffractograms at small (a) and wider (b) angles

a

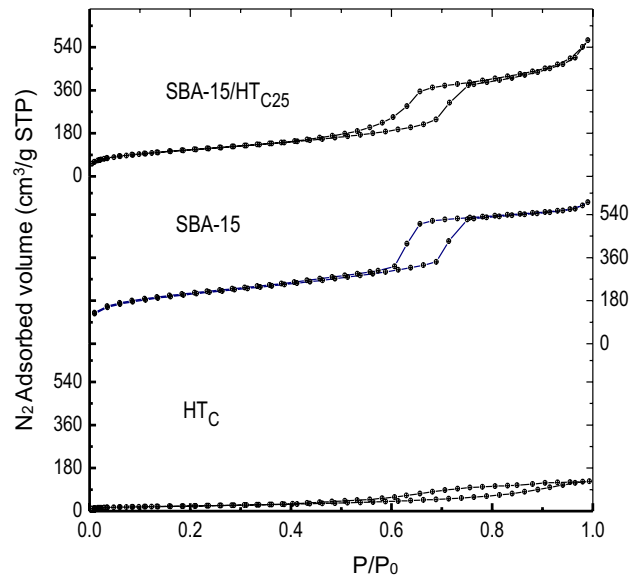

b

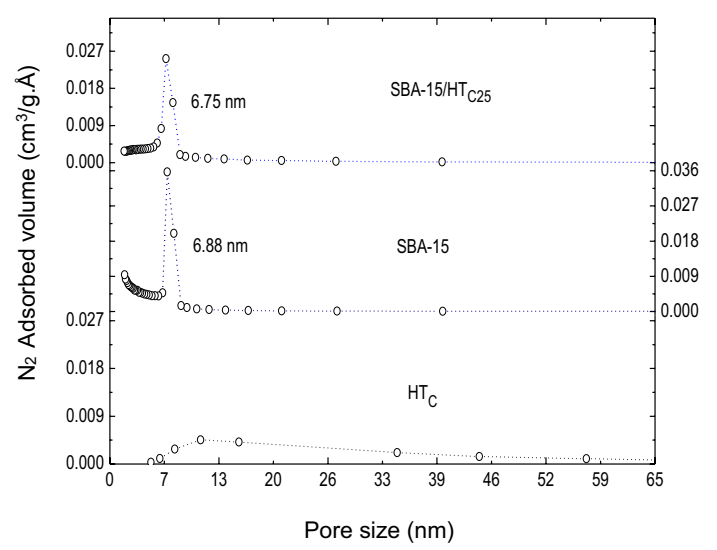

Fig. $2 \mathrm{~N}_{2}$ adsorption isotherms (a) and pore size distribution (b) of the $\mathrm{HT}_{\mathrm{C}}, \mathrm{SBA}-15$, and SBA-15/HT 225

small difference $(0.11 \mathrm{~nm})$ can be related to the particles of the $\mathrm{Mg} / \mathrm{Al}$ mixed oxides that are casting the SBA-15 pores. The specific surface areas were estimated by using the BET method (Brunauer, Emmett and Teller) and the pore diameter distributions were computed by using the BJH method (Barrett, Joyner and
Halenda) applied to the nitrogen desorption isotherm data [18], Table 3. BET surface area decreased (ca. 32\%) in the composite, $402 \mathrm{~m}^{2} / \mathrm{g}$, in comparison to the SBA$15,720 \mathrm{~m}^{2} / \mathrm{g}$; still, it is much bigger than that determined in the HTc $\left(74 \mathrm{~m}^{2} / \mathrm{g}\right)$. Besides, the wall thickness increased from $4.5 \mathrm{~nm}$ (SBA-15) to $4.8 \mathrm{~nm}$ (SBA-15/ 
Table 3 Textural properties of the materials determined from the results of adsorption analysis of $\mathrm{N}_{\mathbf{2}}$ at $77 \mathrm{~K}$

\begin{tabular}{llllll}
\hline Sample & $\begin{array}{l}\text { BET specific surface } \\
\left(\mathbf{m}^{\mathbf{2}} / \mathbf{g}\right)\end{array}$ & Pore volume $\left(\mathbf{c m}^{\mathbf{3}} \mathbf{g}\right)$ & Pore diameter $(\mathbf{n m})$ & $\boldsymbol{d}_{(\mathbf{1 0 0})}(\mathbf{n m})$ & $\mathbf{W T}(\mathbf{n m})$ \\
\hline $\mathrm{HT}_{\mathrm{C}}$ & 74 & 0.19 & Broader $(1-65)$ & - & - \\
$\mathrm{SBA-15}$ & 720 & 0.80 & 6.88 & 10.10 & 4.5 \\
$\mathrm{SBA-15} / \mathrm{HT}_{\mathrm{C} 25}$ & 402 & 0.83 & 6.75 & 9.80 & 4.8 \\
\hline
\end{tabular}

WT wall thickness determined as $\left[\left(2 d 100 /(3)^{0.5}\right)\right.$ - pore diameter]

$\left.\mathrm{HT}_{\mathrm{C} 25}\right)$. Therefore, the $\mathrm{Mg} / \mathrm{Al}$ mixed oxides can form a small layer on the SBA-15 wall surface and the pore size and interlayer parameters are diminished. Moreover, the basic $\mathrm{pH}$ used during the composite preparation may contribute to the loss of the textural properties. Furthermore, the microwave radiation used during synthesis might also have caused a decreased specific BET surface area [11]. Still, the narrow distribution of the average pore diameter and the pore volume remain, Fig. $2 b$, with an increment of the specific surface area and pore volume.

\subsection{BTEX adsorption isotherms}

BTEX adsorption isotherms for the SBA-15 are shown in Fig. 3. In all isotherms, BTEX adsorption is carried out at pressures lower than $5 \mathrm{mmHg}$ because the
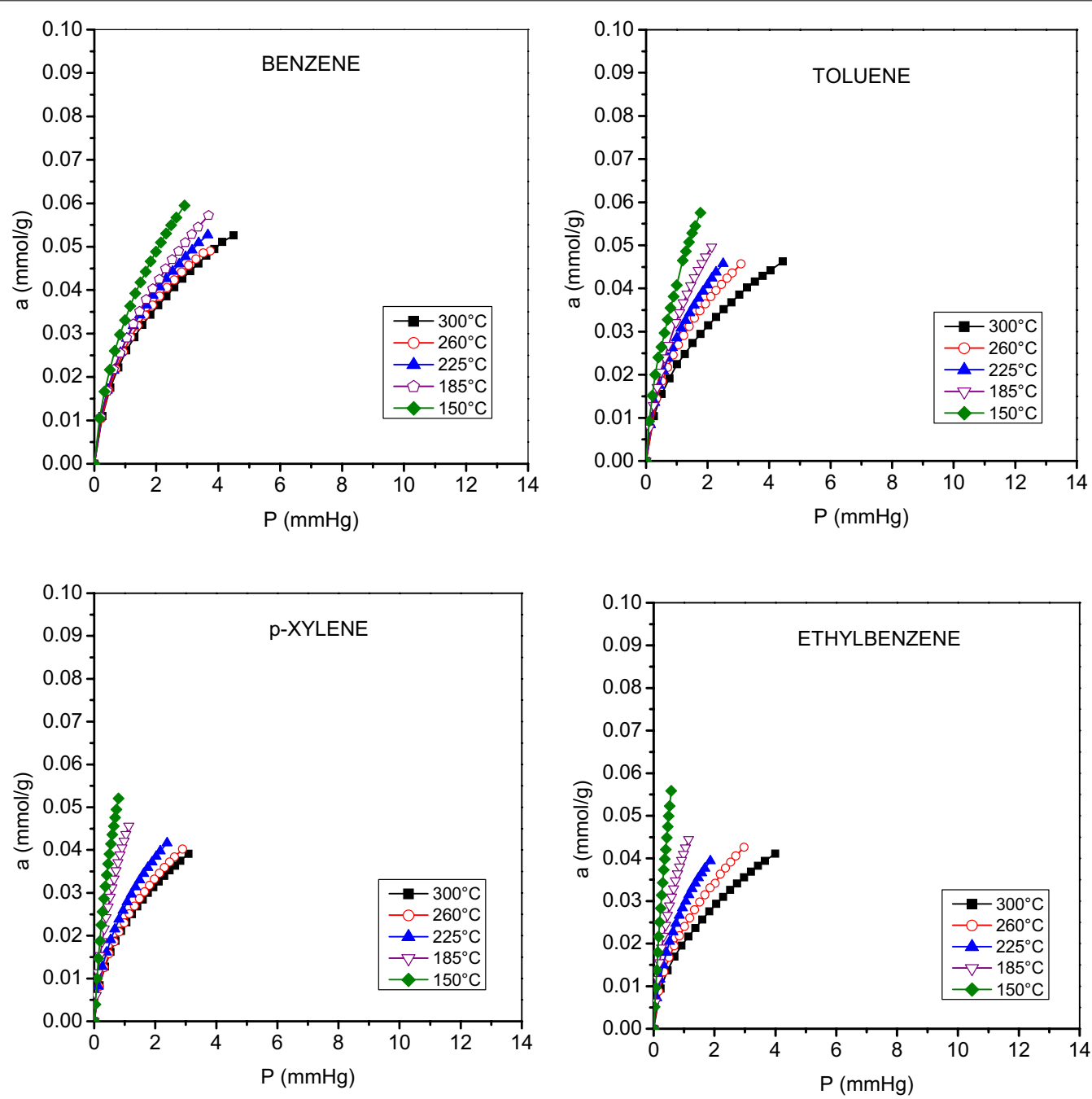

Fig. 3 Benzene, toluene, $p$-xylene, and ethylbenzene adsorption isotherms for SBA-15 
Table 4 Freundlich equation parameters for volatile organic compound (VOC) adsorption in SBA-15, HT, and SBA-15/ $\mathrm{HT}_{\mathrm{C25}}$

\begin{tabular}{|c|c|c|c|c|c|c|c|c|c|c|}
\hline \multirow[t]{2}{*}{ VOCs } & \multirow[t]{2}{*}{$\mathrm{T}\left({ }^{\circ} \mathrm{C}\right)$} & \multicolumn{3}{|c|}{ SBA-15 } & \multicolumn{3}{|l|}{$\mathrm{HT}_{\mathrm{C}}$} & \multicolumn{3}{|c|}{$\mathrm{SBA}-15 / \mathrm{HT}_{\mathrm{C} 25}$} \\
\hline & & $k_{f}$ & $1 / n$ & $R_{f}$ & $k_{f}$ & $1 / n$ & $R_{f}$ & $k_{f}$ & $1 / n$ & $R_{f}$ \\
\hline \multirow[t]{5}{*}{ Benzene } & 300 & 0.024 & 1.884 & 0.994 & 0.017 & 2.325 & 0.998 & 0.03 & 1.658 & 0.994 \\
\hline & 260 & 0.025 & 1.858 & 0.99 & 0.016 & 2.187 & 0.997 & 0.029 & 1.708 & 0.994 \\
\hline & 225 & 0.027 & 1.848 & 0.994 & 0.017 & 2.291 & 0.993 & 0.032 & 1.721 & 0.995 \\
\hline & 185 & 0.027 & 1.738 & 0.998 & 0.017 & 2.281 & 0.997 & 0.033 & 1.633 & 0.995 \\
\hline & 150 & 0.032 & 1.667 & 0.997 & 0.018 & 2.205 & 0.999 & 0.039 & 1.555 & 0.995 \\
\hline \multirow[t]{5}{*}{ Toluene } & 300 & 0.021 & 1.949 & 0.999 & 0.016 & 2.305 & 0.994 & 0.024 & 1.523 & 0.987 \\
\hline & 260 & 0.025 & 1.829 & 0.995 & 0.014 & 2.201 & 0.993 & 0.028 & 1.727 & 0.995 \\
\hline & 225 & 0.027 & 1.732 & 0.995 & 0.013 & 2.139 & 0.997 & 0.031 & 1.663 & 0.996 \\
\hline & 185 & 0.031 & 1.533 & 0.996 & 0.014 & 2.193 & 0.999 & 0.035 & 1.549 & 0.995 \\
\hline & 150 & 0.041 & 1.575 & 0.998 & 0.019 & 2.159 & 0.995 & 0.046 & 1.314 & 0.988 \\
\hline \multirow[t]{5}{*}{ p-Xylene } & 300 & 0.022 & 1.893 & 0.997 & 0.011 & 2.095 & 0.988 & 0.027 & 1.732 & 0.997 \\
\hline & 260 & 0.022 & 1.819 & 0.998 & 0.007 & 2.315 & 0.994 & 0.029 & 1.682 & 0.996 \\
\hline & 225 & 0.026 & 1.786 & 0.997 & 0.013 & 2.206 & 0.997 & 0.034 & 1.541 & 0.994 \\
\hline & 185 & 0.044 & 1.472 & 0.992 & 0.016 & 2.155 & 0.998 & 0.038 & 1.442 & 0.995 \\
\hline & 150 & 0.069 & 1.19 & 0.977 & 0.019 & 2.16 & 0.995 & 0.047 & 1.353 & 0.999 \\
\hline \multirow[t]{5}{*}{ Ethylbenzene } & 300 & 0.02 & 1.951 & 0.999 & 0.014 & 2.152 & 0.976 & 0.026 & 1.764 & 0.999 \\
\hline & 260 & 0.023 & 1.85 & 0.999 & 0.015 & 2.274 & 0.981 & 0.027 & 1.705 & 0.999 \\
\hline & 225 & 0.028 & 1.723 & 0.995 & 0.012 & 2.155 & 0.997 & 0.03 & 1.611 & 0.998 \\
\hline & 185 & 0.042 & 1.527 & 0.99 & 0.015 & 2.201 & 0.998 & 0.039 & 1.391 & 0.989 \\
\hline & 150 & 0.091 & 1.213 & 0.997 & 0.018 & 2.193 & 0.994 & 0.055 & 1.364 & 0.989 \\
\hline
\end{tabular}

Where $T$ is the experimental temperature in $\mathrm{K}, \mathrm{k}_{f}\left(\mathrm{mmHg}^{-1}\right)$ is the value of the Freundlich constant, $1 / n$ is the empirical constant, and $R_{f}$ is the correlation factor

SBA-15 material has a very wide pore diameter $(6.88 \mathrm{~nm}$, shown in Table 4), thus no high pressures are required. The pattern of every isotherm is quite similar to each other. Indeed, the higher the temperature, the lower VOC adsorption occurs. Besides, the adsorbed volume ranges from 0.05 to $0.06 \mathrm{mmol}_{\mathrm{VOCS}} / \mathrm{g}_{\mathrm{SBA}-15}$ at $150{ }^{\circ} \mathrm{C}$. The adsorbate-adsorbent interaction depends on the shape of the isotherm. In these cases, the isotherms are concave. Therefore, as the isotherm presents a concave profile, the BTEX adsorption is ensured, thus, it is confirmed that the SBA-15 uptake of the BTEX compounds favorably. Besides, the lower the temperature, the greater BTEX amount is adsorbed. Furthermore, if the molecular weight of benzene derivatives increases, the adsorption pressure diminishes and its ramification plays a slight role in the uptake amount as a temperature function. Indeed, the ethylbenzene shows higher temperature dependence, than that observed on the benzene adsorption.

BTEX adsorption isotherms of $\mathrm{Mg} / \mathrm{Al}$ hydrotalcite (previously calcined at $550{ }^{\circ} \mathrm{C}$ ) are shown in Fig. 4. Contrary to that observed on the SBA-15, the BTEX uptake on the HTc occurs at higher pressure. Also, as benzene is a nonpolarized hydrophobic molecule and the HTc presents a hydrophilic and low BET specific surface area, no BTEX uptake differences are observed among the temperatures. Still, a major benzene amount is retained on the $\mathrm{HT}_{\mathrm{C}}$, and the $p$-xylene represents the derivate with the lowest adsorbed amount. This behavior is relating to the steric hindrance due to the poor porosity and specific surface area of $\mathrm{HT}_{\mathrm{C}}$ although, a favorable adsorbate-adsorbent interaction is observed, as the isotherms are concave. Furthermore, the increased temperature causes no significant difference in the adsorption pattern. However, the BTEX adsorption is more advantageous at $150{ }^{\circ} \mathrm{C}$ than at the other temperatures, suggesting the physisorption governs this process. Unlike SBA-15, VOC adsorption is carried out at pressures higher than $10 \mathrm{mmHg}$ in the $\mathrm{HT}_{\mathrm{C}}$ as it has a low surface temperature and micropores that prevent BTEX molecules sorption. 

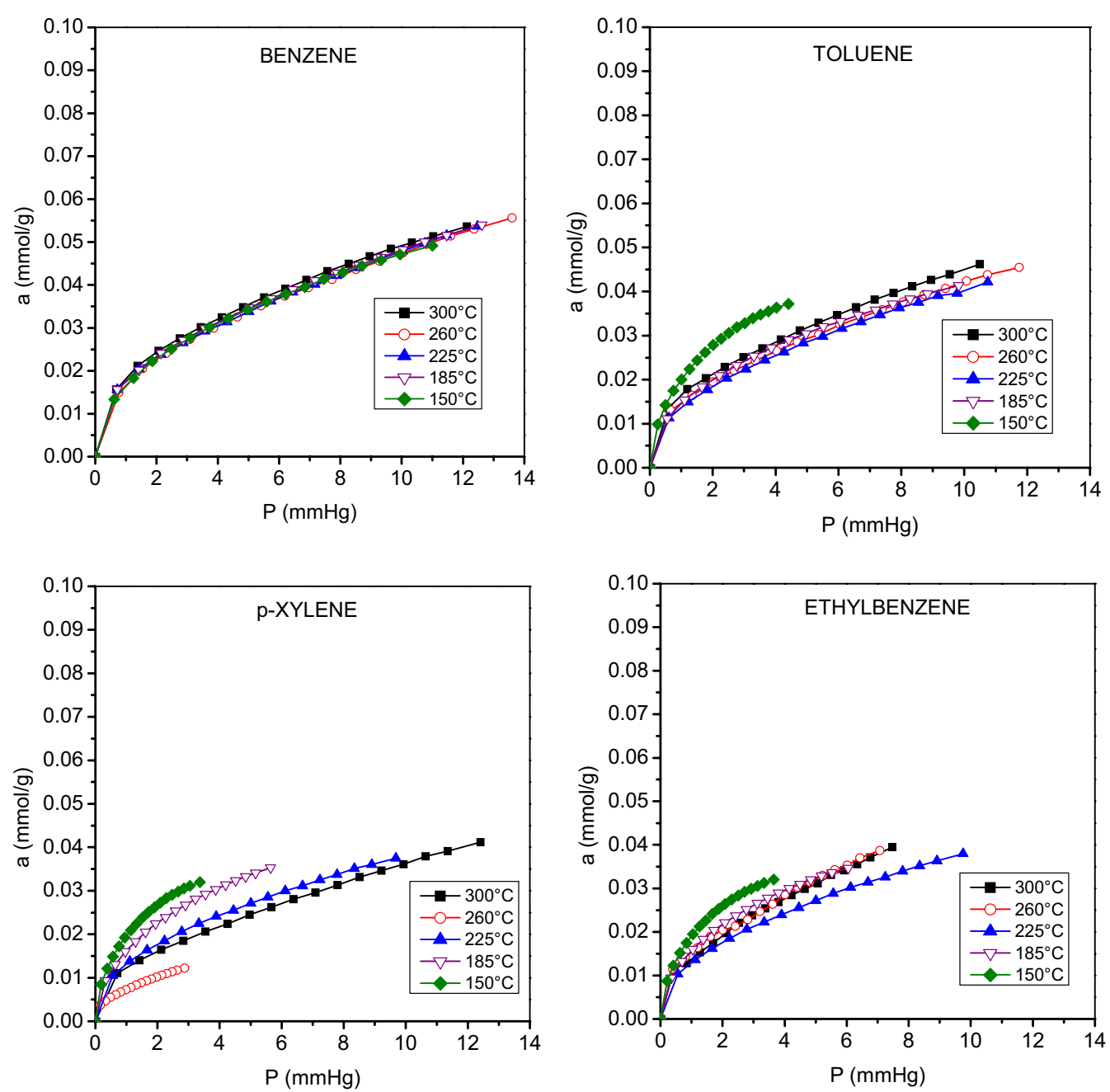

Fig. 4 Benzene, toluene, $p$-xylene, and ethylbenzene adsorption isotherms for $\mathrm{HT}_{\mathrm{C}}$

In Fig. 5 is showed the BTEX adsorption isotherms for the SBA-15/HT $\mathrm{H} 25$ composite. These isotherms have a similar behavior to that of the SBA-15, and again, the most favorable temperature for adsorption is $150{ }^{\circ} \mathrm{C}$. However, this composite has a far higher adsorption level than the one observed in the precursor materials. Indeed, $\mathrm{HT}_{\mathrm{C}}$ and SBA-15 combination boosts VOC adsorption since there is a higher surface interaction owing to the presence of hydrotalcite and a similar mesoporosity to that of SBA-15. Both properties, contribute to a more effective internal diffusion of VOCs. Furthermore, the isotherms show that the composite has a higher affinity to $p$-xylene with an adsorbed volume of $0.095 \mathrm{mmol}_{\mathrm{VOCS}} / \mathrm{g}_{\mathrm{SBA}-15 / \mathrm{HTC} 25}$ and the ethylbenzene is the compound that has the least affinity with an adsorbed volume of $0.055 \mathrm{mmol}_{\mathrm{VOCs}} /$ $\mathrm{g}_{\mathrm{SBA}-15 / \mathrm{HTC25}}$. Hence, no steric hindrance is promoted. Moreover, the isotherms are concave and represent a favorable adsorbate-adsorbent interaction and the increasing of temperature diminishes the BTEX amount sorption. This is readily explained due to the volatile properties of the compounds that are used, as very low vapor pressures. 

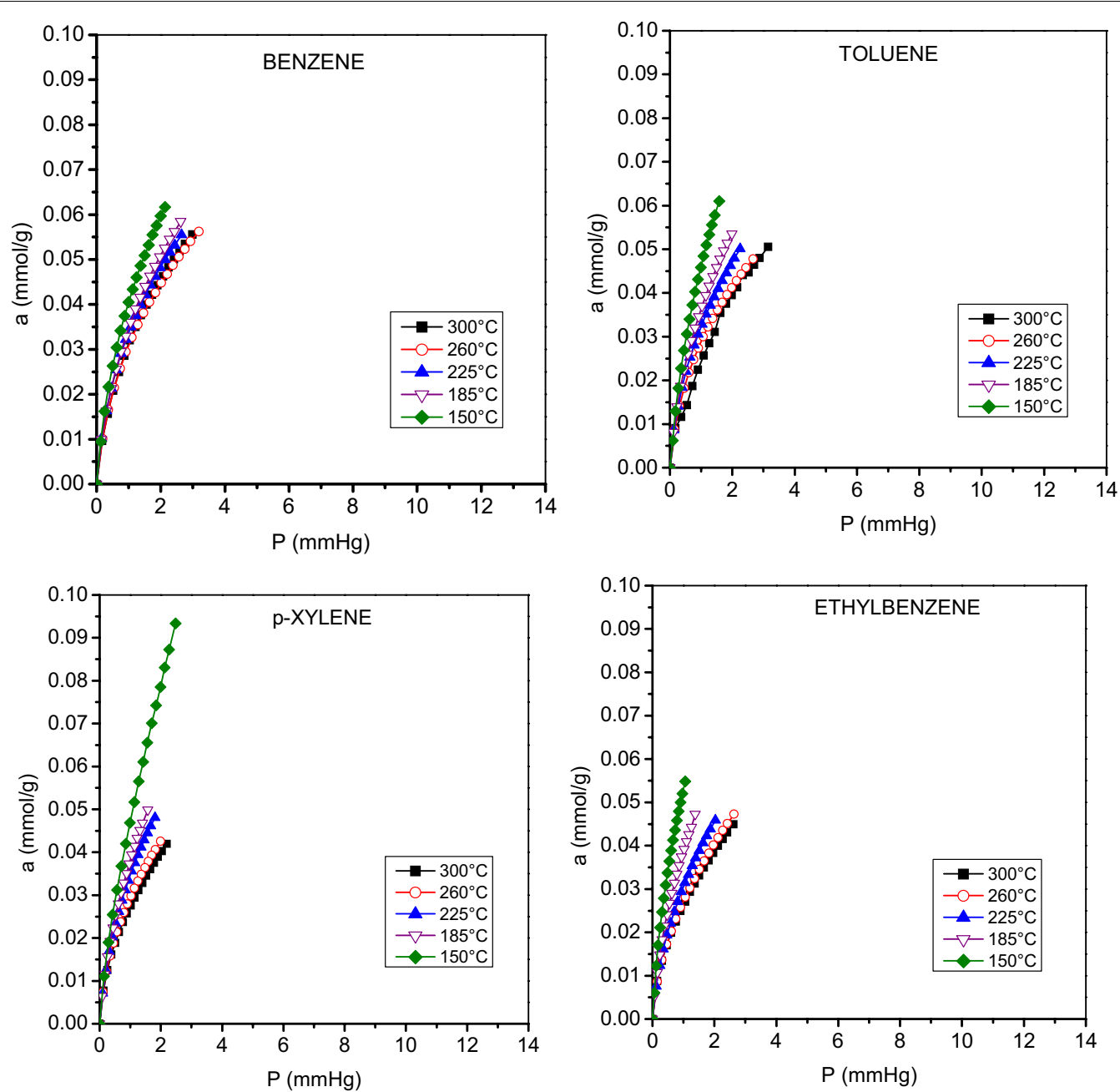

Fig. 5 Benzene, toluene, $p$-xylene, and ethylbenzene adsorption isotherms for SBA-15/HT $\mathrm{C}_{25}$

In the SBA-15/ $\mathrm{HT}_{\mathrm{C} 25}$, VOC adsorption is carried out at pressures lower than $3 \mathrm{mmHg}$. This means that the pore diameter $(6.75 \mathrm{~nm})$ is large enough to prevent an increased relative pressure. However, the increased amount of adsorbed VOCs is higher than in the SBA15 . Hence, it occurs a synergetic adsorbent interaction, as the $\mathrm{Mg} / \mathrm{Al}$ mixed oxides can be well dispersed on the SBA-15 surface [11] with no steric hindrance.

\subsubsection{Freundlich model}

The Freundlich model describes the equilibrium between the solid surface and the BTEX as a multilayer adsorption process. The experimental data obtained from the linear regression of such as isotherms summarized in
Table 4 and Fig. 6, respectively. Freundlich equation is an empirical model that is used to estimate the adsorption behavior of BTEX adsorbed on the nanoporous composites. Although the BTEX Freundlich isotherms, by using the SBA-15 as the adsorbent, Fig. 6, are straightforwardly adjusted to this model, the linearity of $p$-xylene isotherm at $150{ }^{\circ} \mathrm{C}$ is slightly curved, still, the correlation coefficient, $R_{f}=0.997$, shows a marginal error. The adsorption capacity, $k_{f}$ increases as the adsorption temperature decrease and if the temperature is lower than $300{ }^{\circ} \mathrm{C}, k_{f}$ also augments with the adsorbate molecular weight: ethylbenzene $>\mathrm{p}$-xylene $>$ toluene $>$ benzene. Thus, the physisorption is the main adsorption process. SBA-15 is an adsorbent, with an excellent specific surface area and 

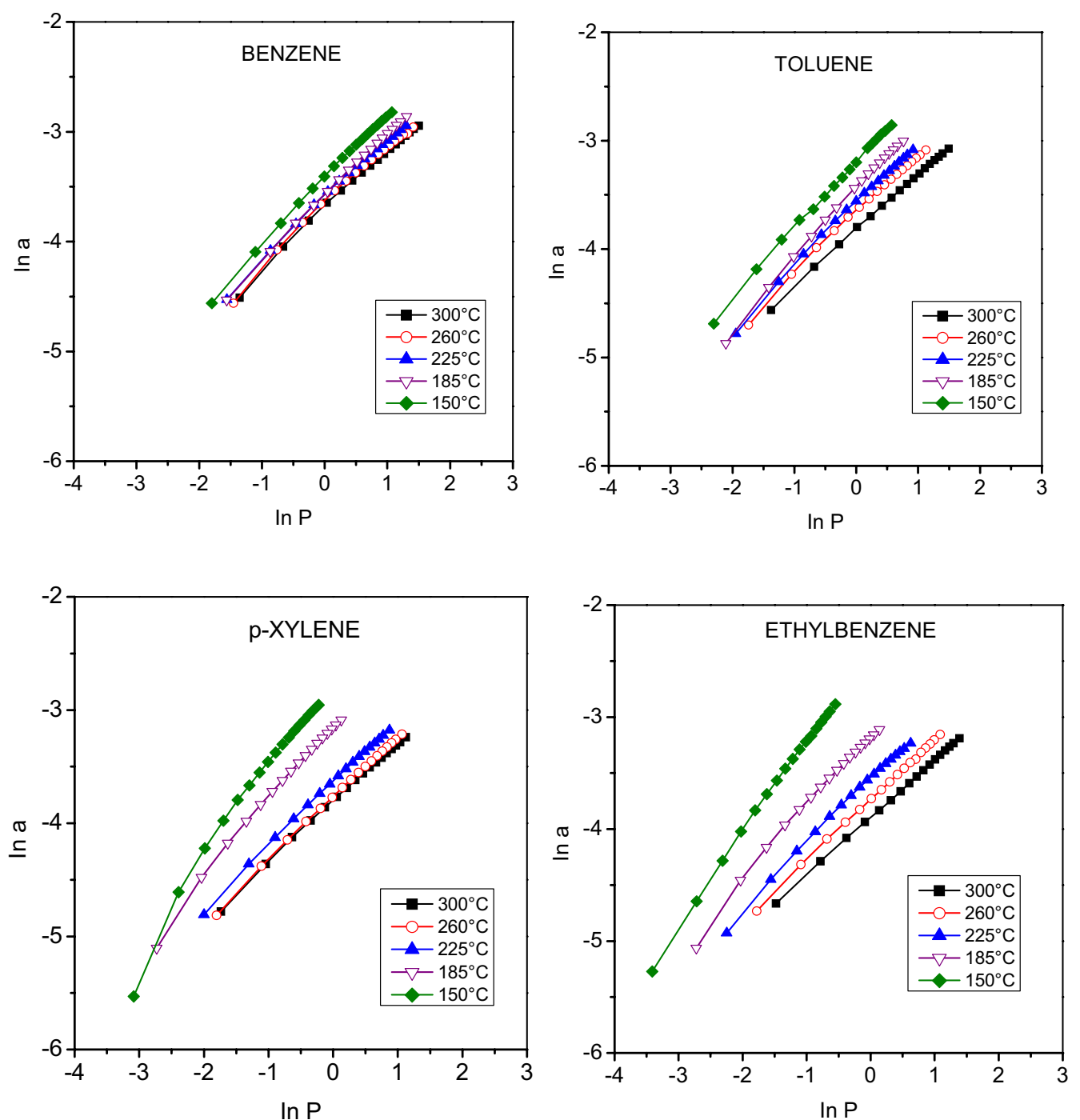

Fig. 6 Benzene, toluene, $p$-xylene, and ethylbenzene adsorption isotherms with the Freundlich model for SBA-15

narrow porous size that diminishes the steric hindrance of the adsorbates. However, the benzene adsorption is constrained by the SBA-15 surface adsorption reactivity, as it should be energetically controlled by the interaction of the molecules with the SBA- 15 pore walls and the number of accessible silanol groups [19].

If the HTc is employed as adsorbent the benzene isotherms are perfectly fitted to the Freundlich model at all temperatures, Fig. 7, indicating no influence of the temperature adsorption during the benzene uptake as the $k_{f}$ values remain almost unchanged, Table 4 .
Toluene isotherms are mostly completely fitted (in all experimental data) with a slight non-linearity at the boundary temperatures $\left(150\right.$ and $300{ }^{\circ} \mathrm{C}$ respectively). Furthermore, the Freundlich model, at 300 and $260{ }^{\circ} \mathrm{C}$, for $p$-xylene and ethylbenzene, shows more variation on the fitting data. However, in all cases, the $R_{f}$ is an indication of an acceptable fitting.

In Fig. 8 is showed the adsorption isotherms with the Freundlich model for the SBA- $15 / \mathrm{HT}_{\mathrm{C} 25}$ composite. The following isotherms are not completely fitted to the Freundlich model: (i) toluene isotherms at 150 and 

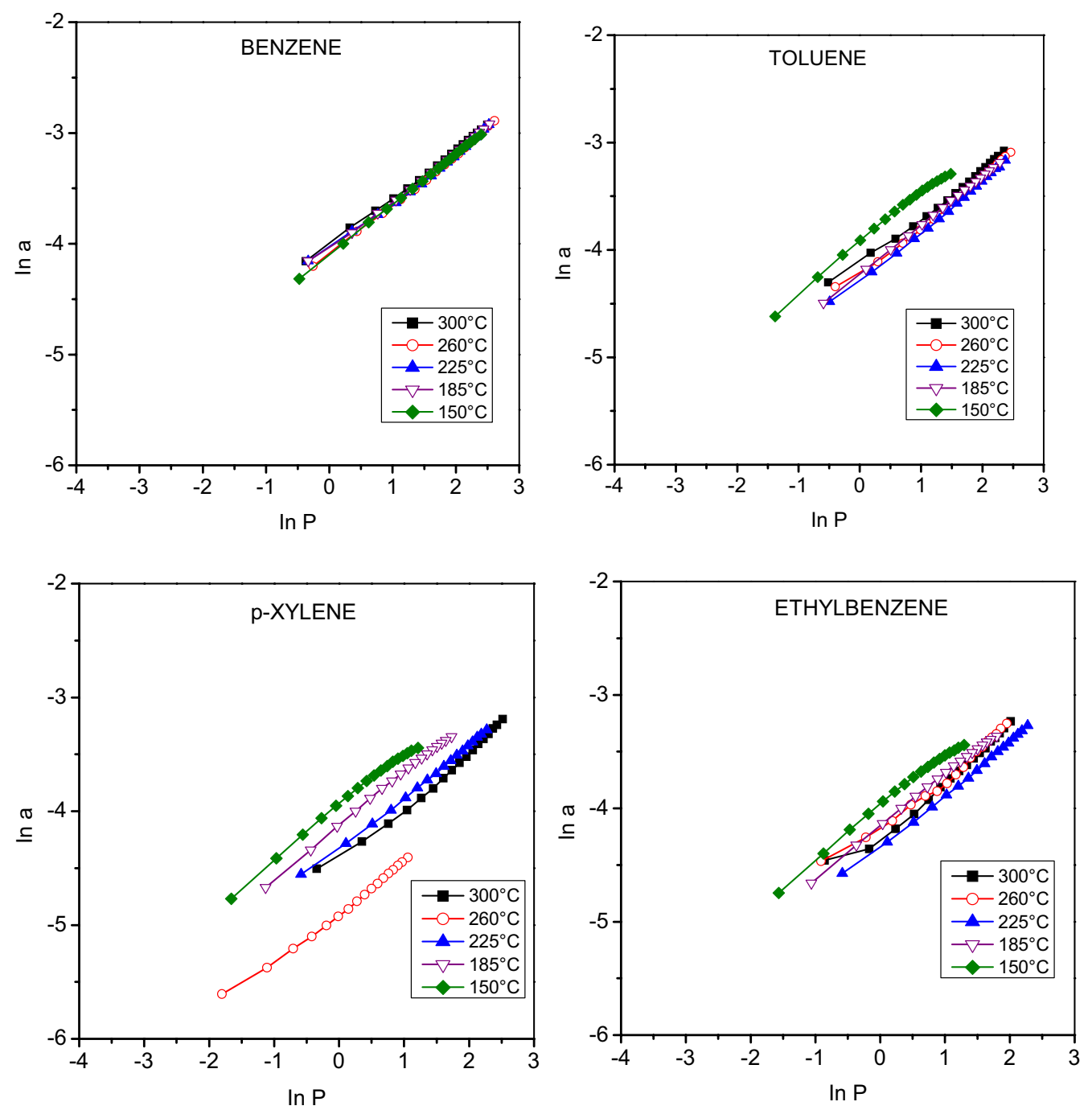

Fig. 7 Benzene, toluene, $p$-xylene, and ethylbenzene adsorption isotherms with the Freundlich model for $\mathrm{HT}_{\mathrm{C}}$

$300{ }^{\circ} \mathrm{C}$, (ii) ethylbenzene isotherms at 150 and $185{ }^{\circ} \mathrm{C}$, and (iii) $p$-xylene isotherm at $150^{\circ} \mathrm{C}$.

All the other isotherms are adjusted to this model, Table 4 . Indeed, it presents a $k_{f}$ and $1 / \mathrm{n}$ values greater than those shown for its precursors, SBA-15 and HTc. Indeed, the $\mathrm{Mg}-\mathrm{Al}$ hydrotalcite prepared in situ of the SBA-15 contributes the increasing of surface reactivity.
In most of the experiments, as the adsorption affinity diminishes $\left(k_{f}\right)$ with the raising of the temperature, as the physisorption is the governing adsorption process, which allows the adsorbent regeneration and low temperature of BTEX sorption. 

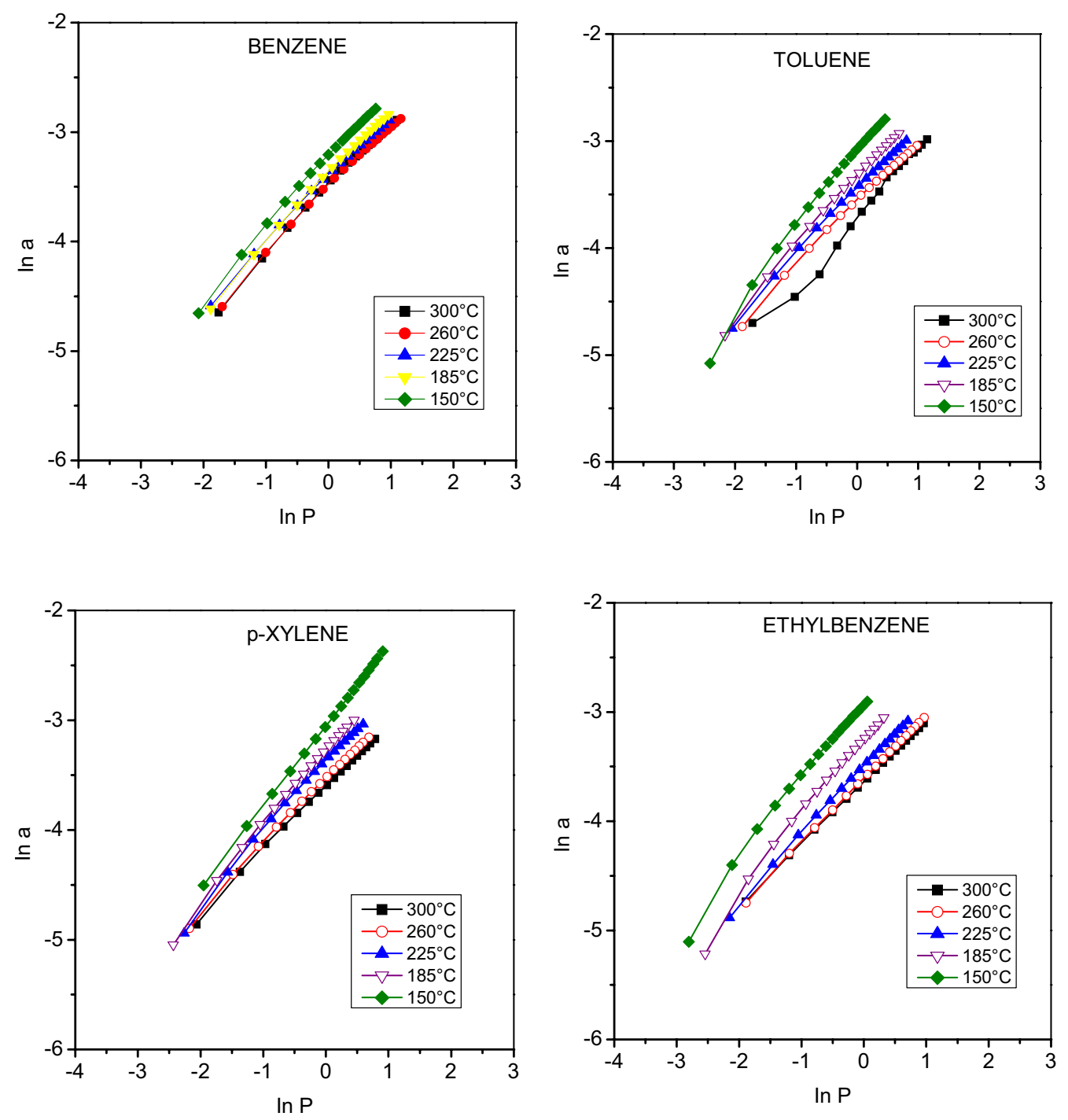

Fig. 8 Benzene, toluene, $p$-xylene, and ethylbenzene adsorption isotherms with the Freundlich model for SBA-15/HT $\mathrm{C}_{\mathrm{C} 25}$

\subsubsection{Langmuir model}

This model describes the ideal equilibrium between a surface (adsorbent) and a chemical substance in a solution (adsorbate) as a monolayer adsorption. In Figs. 9, 10 and 11 are showed the adsorption isotherms with the Langmuir model for the four BTEX in the SBA-15, HTc and SBA-15/HT $\mathrm{H}_{\mathrm{C} 5}$, respectively. In most them, a short curvature is observed, then, these isotherms are neither completely linear, nor completely fitted to the model.

Although the linear correlation coefficient, $\boldsymbol{R}_{L}$, tends to have more variations in comparison to the correlation coefficient of the Freundlich model, the experimental data are partly fitted, to the Langmuir model, 

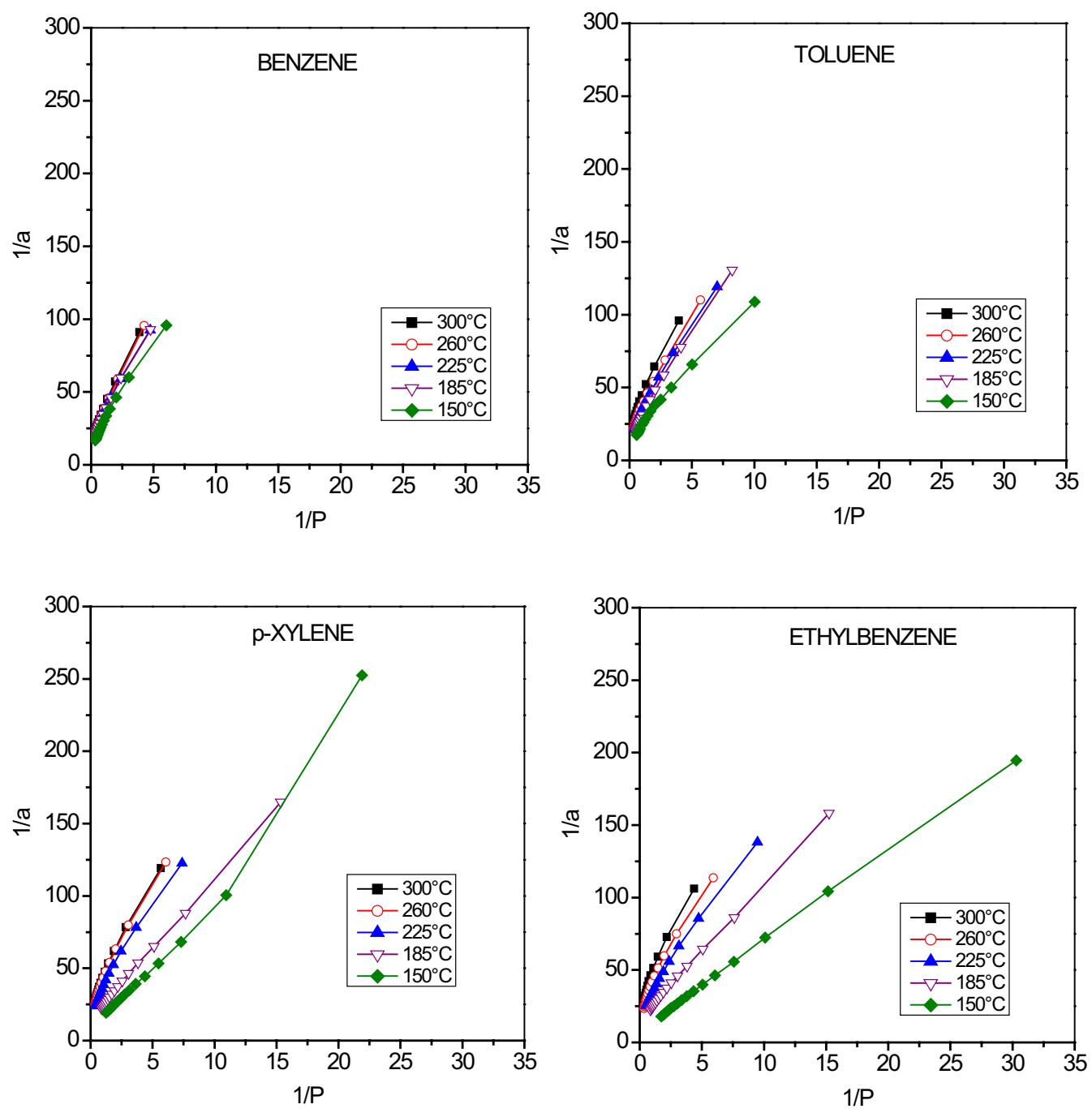

Fig. 9 Benzene, toluene, $p$-xylene, and ethylbenzene adsorption isotherms with the Langmuir model for SBA-15

Table 5, and the physisorption is the predominant adsorption process.

The maximum BTEX amount that the materials can adsorb at the equilibrium is indicated by the monolayer capacity, $\boldsymbol{a}_{\boldsymbol{m}}$. Such values confirm that the materials have a higher affinity to benzene and toluene, if the temperature is lower than $300{ }^{\circ} \mathrm{C}$, while $p$-xylene and ethylbenzene have less adsorption affinity if temperature increases. Indeed, with the increasing of the weight molecular and the temperature different pressure and 

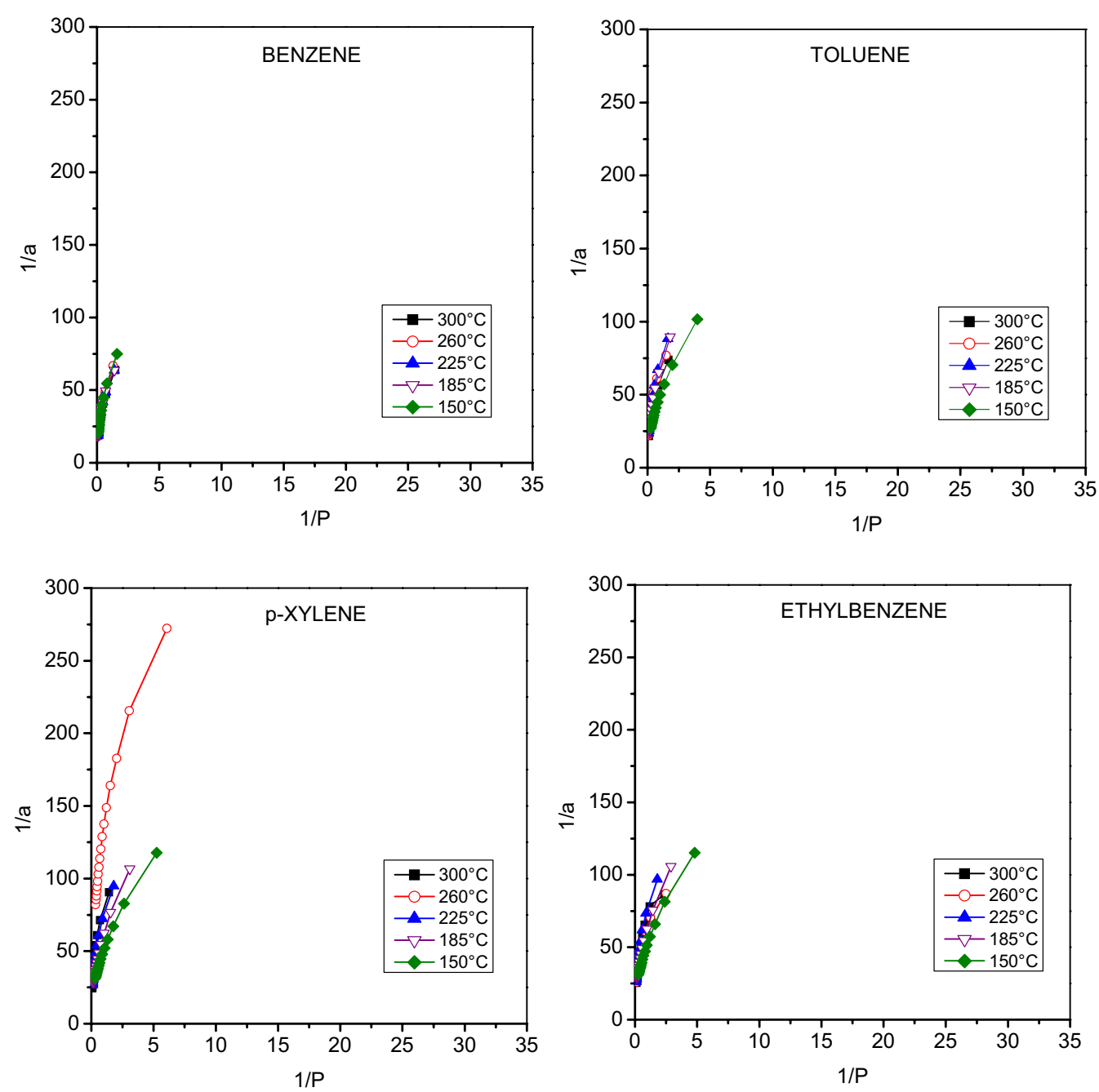

Fig. 10 Benzene, toluene, $p$-xylene, and ethylbenzene adsorption isotherms with the Langmuir model for HTc

adsorption capacity, $a$, are observed. As expected, at low temperature the BTEX amount adsorption increases and the composite, SBA- $15 / \mathrm{HT}_{\mathrm{C} 25}$ exhibits a greater adsorption capacity.

\subsection{Isosteric heats of adsorption}

As adsorption is an exothermic process, increasing the temperature and keeping the constant pressure enhancement adsorbate desorption. In some systems, physisorption is the predominant process at low temperatures, whereas chemisorption is present at high temperatures [6]. In Fig. 12 are plotted benzene, toluene, $p$-xylene, and ethylbenzene isosteric heats of adsorption in the three materials studied: SBA-15, HTc and SBA-15/HT $\mathrm{H}_{\mathrm{C} 25}$. In the four cases, the isosteric heats of adsorption are smaller than the vaporization heat $\left(\Delta \mathrm{H}_{\mathrm{vap}}\right)$ of each one of the VOC adsorbed. This confirms that only a physisorption process is carried out. The values for the SBA15 and the composite profile have an upward behavior, which shows that they present a homogeneous superficial 

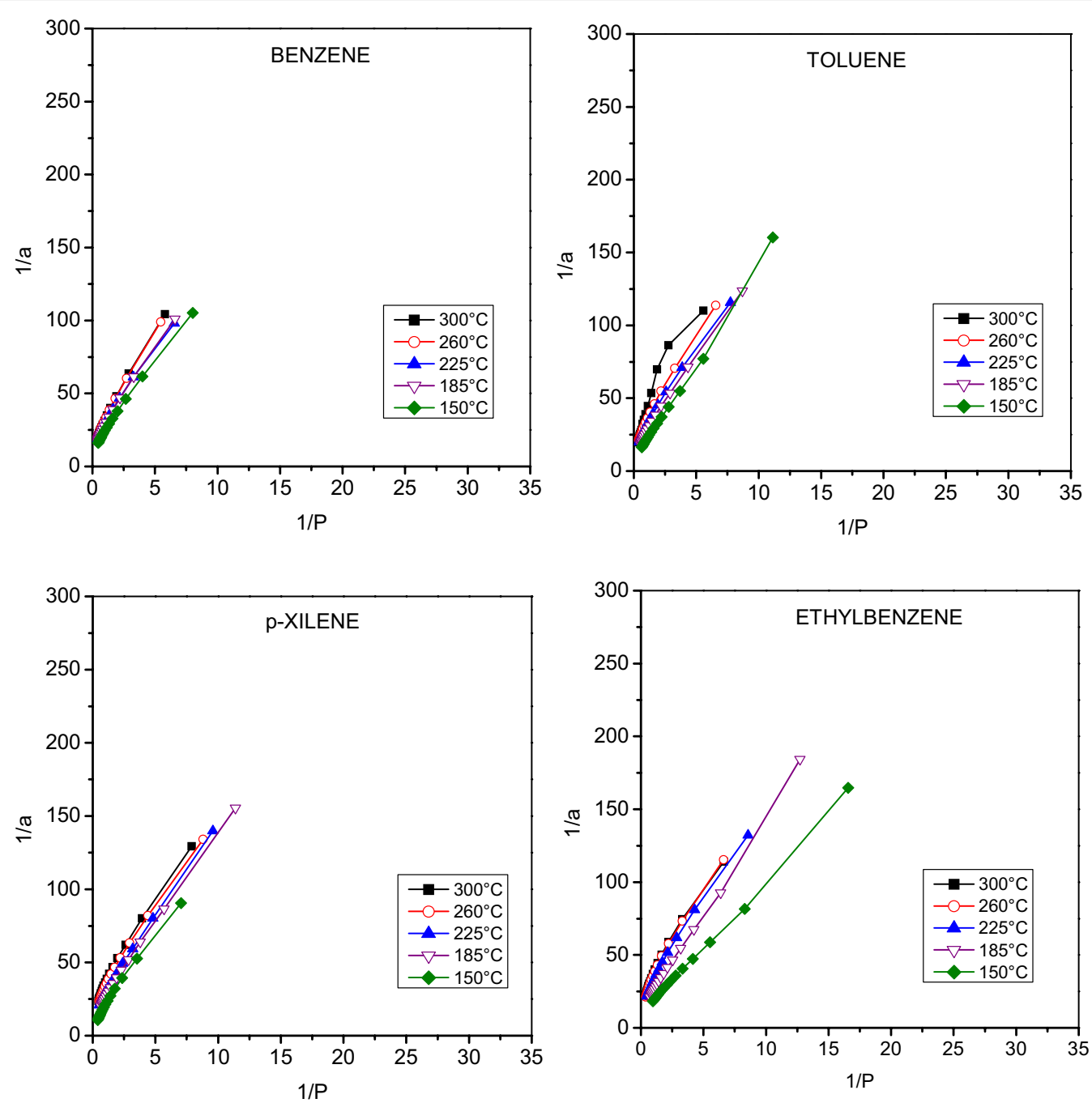

Fig. 11 Benzene, toluene, $p$-xylene, and ethylbenzene adsorption isotherms with the Langmuir model for SBA-15/HT $\mathrm{C}_{\mathrm{C} 25}$

surface. However, $\mathrm{HT}_{\mathrm{C}}$ isotherms have a downward behavior, which indicates a heterogeneous superficial surface.

Table 6 displays both the values of standard adsorption energy $-\Delta U_{0}$ and the isosteric heat or differential enthalpy, which allow describing the energy changes and determining the spontaneity of the adsorption process on the surface of the material.

The isosteric heat is higher than the free adsorption energy of the VOC thus, the molecules interact strongly with both the neighboring surface and the adsorbate molecules. Still, benzene shows the lowest isosteric heat and may favor a repulsive interaction between the adsorbed benzene molecules [20]. Hence, the adsorption uptake on materials is also lower than that observed for the other adsorbates.

In composite, $\mathrm{SBA}-15 / \mathrm{HT}_{\mathrm{C} 25}$, the isosteric heat presents values between those measured for the pristine materials, indicating that the surface reactivity has characteristics of both, SBA-15 and $\mathrm{HT}_{\mathrm{C}}$, respectively. 
Table 5 Langmuir and Henry model parameters for volatile organic compound (VOC) adsorption in SBA-15, $\mathrm{HT}_{\mathrm{C}}$ and SBA-15/HT ${ }_{\text {C25 }}$

\begin{tabular}{|c|c|c|c|c|c|c|c|c|c|c|c|c|c|}
\hline \multirow[t]{2}{*}{ VOCs } & \multirow[t]{2}{*}{$\mathrm{T}\left({ }^{\circ} \mathrm{C}\right)$} & \multicolumn{4}{|c|}{ SBA-15 } & \multicolumn{4}{|l|}{$\mathrm{HT}_{\mathrm{C}}$} & \multicolumn{4}{|c|}{$\mathrm{SBA}-15 / \mathrm{HT}_{\mathrm{C} 25}$} \\
\hline & & $a_{m}$ & $K_{L}$ & $K_{H}$ & $R_{L}$ & $a_{m}$ & $K_{L}$ & $K_{H}$ & $R_{L}$ & $a_{m}$ & $K_{L}$ & $K_{H}$ & $R_{L}$ \\
\hline \multirow[t]{5}{*}{ Benzene } & 300 & 0.059 & 0.852 & 0.05 & 0.99 & 0.05 & 0.586 & 0.029 & 0.93 & 0.068 & 0.915 & 0.062 & 0.993 \\
\hline & 260 & 0.06 & 0.872 & 0.052 & 0.994 & 0.052 & 0.468 & 0.024 & 0.935 & 0.067 & 0.935 & 0.062 & 0.993 \\
\hline & 225 & 0.059 & 1.012 & 0.06 & 0.988 & 0.049 & 0.577 & 0.028 & 0.907 & 0.067 & 1.168 & 0.076 & 0.991 \\
\hline & 185 & 0.063 & 0.919 & 0.058 & 0.984 & 0.05 & 0.559 & 0.028 & 0.916 & 0.071 & 1.021 & 0.073 & 0.992 \\
\hline & 150 & 0.069 & 1.025 & 0.071 & 0.988 & 0.048 & 0.564 & 0.027 & 0.95 & 0.081 & 1.04 & 0.084 & 0.996 \\
\hline \multirow[t]{5}{*}{ Toluene } & 300 & 0.048 & 1.026 & 0.049 & 0.974 & 0.042 & 0.701 & 0.029 & 0.906 & 0.052 & 1.00 & 0.052 & 0.91 \\
\hline & 260 & 0.051 & 1.179 & 0.06 & 0.99 & 0.041 & 0.583 & 0.024 & 0.898 & 0.055 & 1.188 & 0.065 & 0.99 \\
\hline & 225 & 0.053 & 1.271 & 0.067 & 0.991 & 0.039 & 0.583 & 0.023 & 0.922 & 0.059 & 1.272 & 0.075 & 0.991 \\
\hline & 185 & 0.064 & 1.075 & 0.068 & 0.992 & 0.04 & 0.629 & 0.025 & 0.95 & 0.07 & 1.11 & 0.077 & 0.996 \\
\hline & 150 & 0.067 & 1.538 & 0.103 & 0.989 & 0.039 & 1.23 & 0.048 & 0.974 & 0.131 & 0.564 & 0.074 & 0.997 \\
\hline \multirow[t]{5}{*}{ p-Xylene } & 300 & 0.042 & 1.335 & 0.056 & 0.981 & 0.036 & 0.524 & 0.019 & 0.885 & 0.047 & 1.469 & 0.07 & 0.988 \\
\hline & 260 & 0.043 & 1.316 & 0.057 & 0.981 & 0.011 & 2.58 & 0.028 & 0.898 & 0.049 & 1.498 & 0.074 & 0.99 \\
\hline & 225 & 0.046 & 1.514 & 0.069 & 0.984 & 0.035 & 0.675 & 0.023 & 0.922 & 0.064 & 1.178 & 0.075 & 0.997 \\
\hline & 185 & 0.067 & 1.509 & 0.102 & 0.999 & 0.036 & 1.002 & 0.036 & 0.962 & 0.070 & 1.122 & 0.079 & 0.998 \\
\hline & 150 & 0.078 & 1.117 & 0.092 & 0.981 & 0.033 & 1.635 & 0.055 & 0.972 & 0.124 & 0.666 & 0.082 & 0.991 \\
\hline \multirow[t]{5}{*}{ Ethylbenzene } & 300 & 0.041 & 1.185 & 0.048 & 0.965 & 0.033 & 0.987 & 0.033 & 0.818 & 0.048 & 1.387 & 0.066 & 0.977 \\
\hline & 260 & 0.044 & 1.379 & 0.06 & 0.976 & 0.034 & 1.089 & 0.037 & 0.866 & 0.051 & 1.258 & 0.065 & 0.981 \\
\hline & 225 & 0.046 & 1.7 & 0.078 & 0.99 & 0.035 & 0.644 & 0.023 & 0.925 & 0.054 & 1.33 & 0.072 & 0.989 \\
\hline & 185 & 0.062 & 1.701 & 0.105 & 0.999 & 0.035 & 0.974 & 0.034 & 0.962 & 0.081 & 0.921 & 0.074 & 0.998 \\
\hline & 150 & 0.120 & 1.317 & 0.16 & 0.999 & 0.035 & 1.535 & 0.052 & 0.972 & 0.101 & 1.069 & 0.108 & 0.998 \\
\hline
\end{tabular}

Langmuir monolayer capacity $\mathrm{a}_{\mathrm{m}}(\mathrm{mmol} / \mathrm{g})$, adsorbent's maximum adsorption capacity, Henry constants $\mathrm{K}_{\mathrm{H}}\left(\mathrm{mmHg}^{-1}\right)$, Langmuir $\mathrm{K}_{\mathrm{L}}\left(\mathrm{mmHg}^{-1}\right)$, and $\mathrm{R}_{\mathrm{L}}$ linear correlation coefficient

Certainly, the $\mathrm{Mg}$ and $\mathrm{Al}$ mixed oxides favorably modify the reactivity of the SBA-15 surface and the perseveration of its nanostructure contribute to the BTEX sorption at low temperature, as no steric hindrance occurs.

\section{Conclusions}

The SBA- $15 / \mathrm{HT}_{\mathrm{C} 25}$ composite presented a good effective BTEX adsorption performance as the nanostructure and $\mathrm{Mg}-\mathrm{Al}$ oxides enhance its surface reactivity, improving the BTEX sorption. Therefore, the physicochemical properties of both materials present a synergistic collaboration, in terms of their surface reactivity, that improves the adsorption process. The adsorption isotherms obtained from the adsorbent materials are mainly fitted to the experimental Freundlich adsorption pattern and the VOC are favorably adsorbed, as physisorption process is predominant. Furthermore, these materials can be reused for more time without losing their structural properties and without being affected by adsorption. Composites 

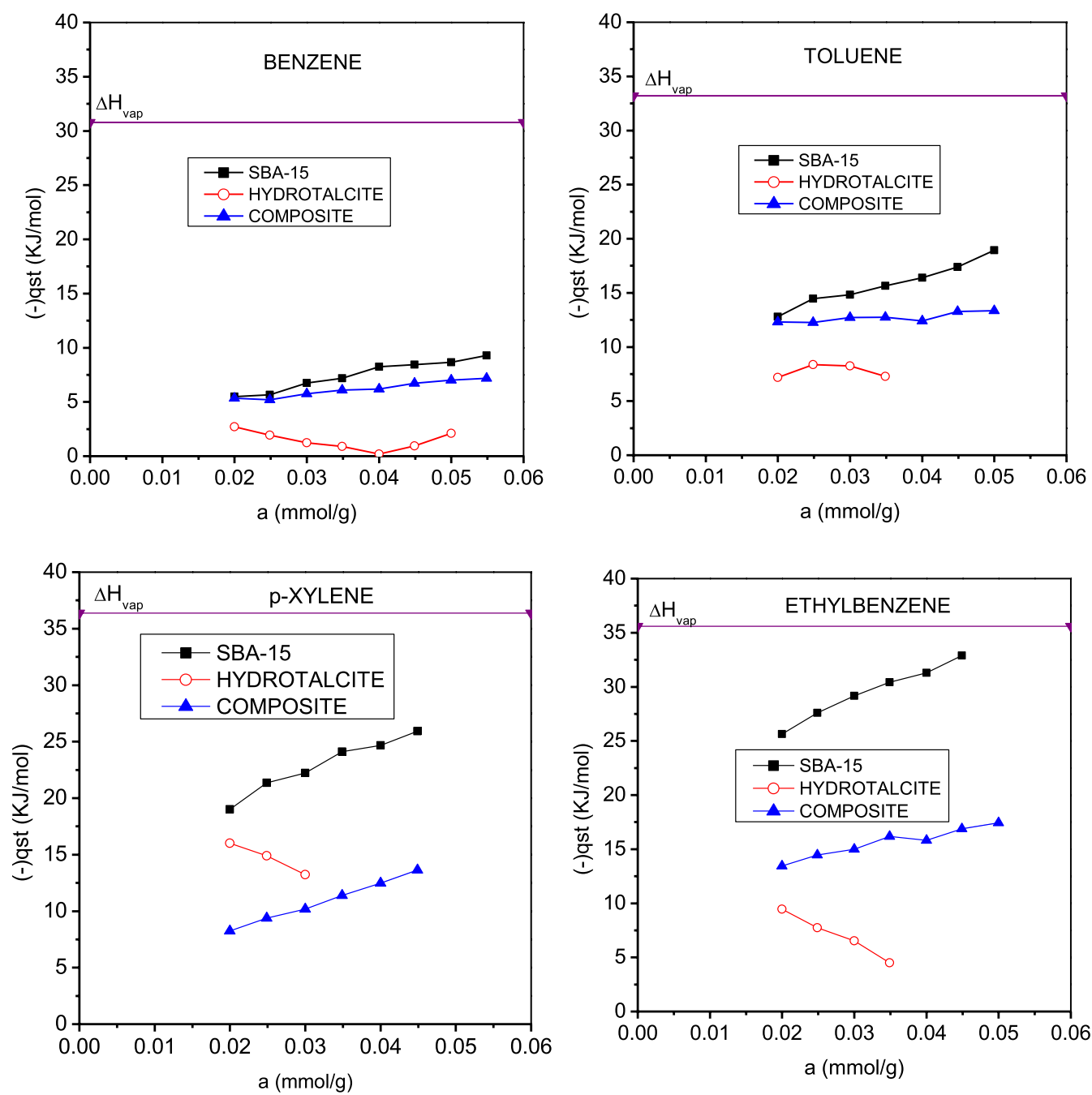

Fig. 12 Isosteric heats of adsorption of benzene, toluene, $p$-xylene, and ethylbenzene for SBA-15, $\mathrm{HT}_{C}$, and SBA-15/HT $\mathrm{C}_{\mathrm{C}}$, respectively

Table 6 Values of the free standard adsorption energy and the isosteric heats of adsorption

\begin{tabular}{|c|c|c|c|c|c|c|c|c|}
\hline & \multicolumn{2}{|c|}{ Benzene } & \multicolumn{2}{|c|}{ Toluene } & \multicolumn{2}{|c|}{$p$-Xylene } & \multicolumn{2}{|c|}{ Ethylbenzene } \\
\hline & $-\Delta \mathrm{U}_{0}$ & $-q_{s t}$ & $-\Delta \mathrm{U}_{0}$ & $-q_{s t}$ & $-\Delta U_{0}$ & $-q_{s t}$ & $-\Delta U_{0}$ & $-q_{s t}$ \\
\hline SBA-15 & 4.766 & 9.294 & 8.997 & 18.926 & 6.848 & 25.921 & 15.743 & 32.897 \\
\hline$H T_{C}$ & -1.166 & -2.711 & 7.538 & 8.374 & 13.627 & 16.013 & 5.905 & 9.449 \\
\hline $\mathrm{SBA}-15 / \mathrm{HT}_{\mathrm{C} 25}$ & 4.348 & 7.182 & 10.926 & 13.341 & 2.094 & 13.631 & 2.109 & 17.438 \\
\hline
\end{tabular}

Standard adsorption energy $\left(\Delta \mathrm{U}_{0}, \mathrm{~kJ} / \mathrm{mol}\right)$ and isosteric heats of adsorption $\left(\mathrm{q}_{\mathrm{st}}, \mathrm{kJ} / \mathrm{mol}\right)$ of volatile organic compounds 
prepared from SBA-15 and HTc open new ways to produce materials with physicochemical improved properties that enhance the VOC adsorption process without a steric hindrance of the adsorbates.

\section{Authors' contributions}

RINF carried out most of the experiments at the Benemérita Universidad Autónoma de Puebla. All authors contributed to writing, reading and agreeing on the final version of the manuscript. All authors read and approved the final manuscript.

\section{Author details \\ ${ }^{1}$ Facultad de Ingeniería Química, Benemérita Universidad Autónoma de Puebla, Ciudad Universitaria, 72570 Puebla, PUE, Mexico. ${ }^{2}$ Departamento de Investigación en Zeolitas del Instituto de Ciencias, Benemérita Universidad Autónoma de Puebla, Ciudad Universitaria, 72570 Puebla, PUE, Mexico.}

\section{Competing interests}

The authors declare that they have no competing interests.

\section{Ethics approval and consent to participate}

Not applicable.

\section{Funding}

The financial support of CONACYT (Project 180166) is gratefully acknowledged.

\section{Publisher's Note}

Springer Nature remains neutral with regard to jurisdictional claims in published maps and institutional affiliations.

Received: 1 June 2018 Accepted: 7 July 2018

Published online: 02 August 2018

\section{References}

1. Agency for Toxic Substances and Disease Registry, ATSDR. (2007), https ://www.atsdr.cdc.gov/toxprofiles/index.asp\#B. Retrieved 31 August 2017

2. M.S. Kamal, S.A. Razzak, M.H. Hossain, Catalytic oxidation of volatile organic compounds (VOCs). Atmos. Environ. 40, 117-134 (2016)

3. C. He, P. Li, J. Cheng, Z.P. Hao, Z.P. Xu, A comprehensive study of deep catalytic oxidation of benzene, toluene, ethylacetate, and their mixtures over Pd/ZSM-5 catalyst: mutual effects and kinetics. Water Air Soil Pollut. 209, 365-376 (2010)

4. F.I. Khan, A.K. Ghoshal, Removal of volatile organic compounds from polluted air. J. Loss Prev. Process Ind. 13, 527-545 (2000)
5. K. Yang, Q. Sun, F. Xue, D.Adsorption Lin, Adsorption of volatile organic compounds by metal-organic frameworks MIL-101: influence of molecular size and shape. J. Hazard. Mater. 195, 124-131 (2011)

6. M.A. Hernández, M. Asomoza, F. Rojas, S. Solís, R. Portillo, M.A. Salgado, C. Felipe, Y. Portillo, F. Hernández, Trapping of BTX compounds by $\mathrm{SiO}_{2}$, $\mathrm{Ag}-\mathrm{SiO}_{2}, \mathrm{Cu}-\mathrm{SiO}_{2}$, and $\mathrm{Fe}-\mathrm{SiO}_{2}$ porous substrates. Chemosphere 81, 876-883 (2010)

7. H. Lu, J. Cao, Y. Zhou, D. Zhan, Y. Chen, Novel hydrophobic PDVB/R-SiO, for adsorption of volatile organic compounds from highly humid gas stream. J. Hazard. Mater. 262, 83-90 (2013)

8. B. Dou, Q. Hu, J. Li, S. Qiao, Z. Hao, Adsorption performance of VOCs in ordered mesoporous silicas with different pore structures and surface chemistry. J. Hazard. Mater. 186, 1615-1624 (2011)

9. C. Gennequin, T. Barakat, H.L. Tidahy, R. Cousin, J.-F. Lamonier, A. Aboukaïs, S. Siffert, Use and observation of the hydrotalcite "memory effect" for VOC oxidation. Catal. Today 157, 191-197 (2010)

10. F. Cavani, F. Trifirò, A. Vaccari, Hydrotalcite-type anionic clays: preparation, properties and applications. Catal. Today 11, 173-301 (1991)

11. A. Pérez-Verdejo, A. Sampieri, H. Pfeiffer, M. Ruiz-Reyes, J.D. Santamaría, G. Fetter, Nanoporous composites prepared by a combination of SBA-15 with Mg-Al mixed oxides. Water vapor sorption properties. Beilstein J. Nanotechnol. 5, 1226-1234 (2014)

12. O. Anunziata, M. Martínez, A. Beltramone, Hydroxyapatite/MCM-41 and SBA-15 nano-composites: preparation, characterization and applications. Materials 2, 1508-1519 (2009)

13. D.Y. Zhao, Q.S. Huo, J.L. Feng, B.F. Chmelka, G.D. Stucky, Nonionic triblock and star diblock copolymer and oligomeric surfactant syntheses of highly ordered, hydrothermally stable, mesoporous silica structures. J. Am. Chem. Soc. 120, 6025-6038 (1998)

14. A. Sampieri, G. Fetter, H. Pfeiffer, P. Bosch, Carbonate phobic (Zn, Mn)-Al hydrotalcite-like compounds. Solid State Sci. 9, 394-403 (2007)

15. J. Riddick, W. Bunger, T. Sakano, Organic Solvents Physical Properties and Methods of Purification (Wiley, New York, 1986)

16. D.M. Ruthven, Principles of Adsorption and Adsorption Processes (Wiley, New York, 1984)

17. G. Rouquerol, J. Rouquerol, K. Sing, Adsorption by Powders and Porous Solids (Academic Press, London, 1999)

18. K.S.W. Sing, Adsorption methods for the characterization of porous materials. Adv. Coll. Interface Sci. 76-77, 3-11 (1998)

19. M. Ide, M. El-Roz, E. De Canck, A. Vicente, T. Planckaert, T. Bogaerts, I. Van Driessche, F. Lynen, V. Van Speybroeck, F. Thybault-Starzykb, P. Van Der Voort, Quantification of silanol sites for the most common mesoporous ordered silicas and organosilicas: total versus accessible silanols. Phys. Chem. Chem. Phys. 15, 642-650 (2013)

20. H. Zaitan, A. Korrir, T. Chafik, D. Banchi, Evaluation of volatile organic compound (di-methyl-benzene) removal using adsorption on natural minerals compared to comerical oxides. J. Hazard. Mater. 262, 365-376 (2013)

\section{Submit your manuscript to a SpringerOpen ${ }^{\odot}$ journal and benefit from:}

- Convenient online submission

Rigorous peer review

- Open access: articles freely available online

- High visibility within the field

- Retaining the copyright to your article

Submit your next manuscript at springeropen.com 